\title{
Increase in exhaled carbon monoxide during exacerbations of cystic fibrosis
}

\author{
Julio D Antuni, Sergei A Kharitonov, Derralynn Hughes, Margaret E Hodson, \\ Peter J Barnes
}

\begin{abstract}
Background-Non-invasive assessment of inflammation is likely to be useful in the management of cystic fibrosis (CF). Exhaled carbon monoxide (CO) concentrations are increased in patients with clinically stable CF. A study was undertaken to determine whether this marker of oxidative damage is further increased during exacerbations of the disease.

Methods-Exhaled CO concentrations were measured in 12 healthy non-smoking control subjects (six men) of mean (SE) age 37 (2) years with forced expiratory volume in one second $\left(\mathrm{FEV}_{1}\right) 95$ (1)\% predicted and in 44 patients with CF ( 20 men) of mean (SE) age 29 (1) years with FEV 56 (3)\% predicted using an on-line CO analyser.
\end{abstract}

Results-Twenty nine patients were in a stable condition while 15 had clinically defined respiratory exacerbations (increased cough and production of sputum, change in the quality of the sputum, shortness of breath, sensation of chest congestion, and deterioration of $\mathrm{FEV}_{1}$ ) and represented the unstable group. Exhaled CO concentrations were 2.0 $(0.15) \mathrm{ppm}$ in the control group, were increased in the stable CF group to 2.7 (0.13) ppm (differences between means $-0.67(0.22), 95 \%$ confidence interval (CI) 0.22 to $1.12, p<0.01)$ and further increased in the unstable group to $4.8(0.3) \mathrm{ppm}$ (differences between means $-2.15(0.32)$, $95 \%$ CI 1.50 to 2.79 , p<0.001). A significant correlation was found between the deterioration in $\mathrm{FEV}_{1}$ and exhaled $\mathrm{CO}$ concentrations.

Conclusions-This study shows that the measurement of exhaled $\mathrm{CO}$ is of potential value as an indicator of exacerbations in patients with $C F$ and could be used as a simple method to monitor the course of the disease.

(Thorax 2000;55:138-142)

Keywords: carbon monoxide; nitric oxide; cystic fibrosis; exhaled gases

In patients with cystic fibrosis (CF) increased concentrations of markers of oxidative damage to lipids and proteins and lower concentrations of antioxidants in the plasma suggest increased oxidative stress. ${ }^{12}$ There is also evidence for increased oxidative stress in the epithelial lining fluid of patients with $\mathrm{CF}^{34}$ These oxidants activate heme oxygenase-1 ( $\mathrm{HO}-1)$, an enzyme that catalyses the initial reaction in heme catabolism leading to the production of biliverdin, iron, and carbon monoxide (CO). ${ }^{5} \mathrm{Ex}-$ haled $\mathrm{CO}$ concentrations are increased in asthma, ${ }^{6}$ upper respiratory tract infections, ${ }^{7}$ and bronchiectasis, ${ }^{8}$ indicating increased oxidative stress in these inflammatory conditions. We have recently reported an increase in exhaled $\mathrm{CO}$ concentrations in patients with CF. ${ }^{9}$

Nitric oxide (NO) is synthesised in the airways by NO synthase (NOS) ${ }^{10}$ and is rapidly metabolised to nitrite $\left(\mathrm{NO}_{2}\right)$ and nitrate $\left(\mathrm{NO}_{3}\right)$. Exhaled NO concentrations are raised in inflammatory airway diseases, ${ }^{11-13}$ as well as sputum concentrations of $\mathrm{NO}_{2}$ and $\mathrm{NO}_{3} \cdot{ }^{14}$ Surprisingly, exhaled NO concentrations are not increased in patients with $\mathrm{CF}^{15}{ }^{16}$ and the possible explanations for this finding include poor diffusion of $\mathrm{NO}$ across thick and viscous airway secretions, failure of upregulation of epithelial inducible NOS (iNOS), ${ }^{17}$ and reaction of $\mathrm{NO}$ with superoxide to form peroxynitrite, nitrite, and nitrate. ${ }^{19}$ In agreement with the latter hypothesis, Ho et al reported increased levels of nitrite in breath condensate from patients with $\mathrm{CF}^{20}$ There was no difference in sputum concentrations of nitrite or nitrate between CF patients with stable disease and patients with pulmonary exacerbations, ${ }^{21}$ whereas increased sputum concentrations of total nitrite plus nitrate have been reported in acute pulmonary infections in patients with $C F^{22}$

In order to find a reliable marker of respiratory exacerbations other than $\mathrm{NO}$ or its metabolites in patients with CF we hypothesised that HO-1 activity may be increased in response to inflammation and oxidative stress in CF patients who had infective exacerbations, resulting in increased exhaled CO concentrations.

\section{Methods}

SUBJECTS

Twelve healthy non-smoking subjects were included in the normal control group. They were free of respiratory disease, with no upper or lower airway infection within the last four weeks, and presented with normal spirometric values. Forty four patients with a diagnosis of cystic fibrosis from the CF Clinic of the Royal Brompton Hospital were evaluated for the patient group. Patients with a severe exacerbation, asthma, upper respiratory tract infection within the last four weeks, cigarette smoking, liver disease (CF related or other aetiology), haemolytic anaemia, or inability to perform an 
Table 1 Subject characteristics

\begin{tabular}{llll}
\hline & \multicolumn{3}{c}{$C F$} \\
\cline { 3 - 4 } & $\begin{array}{l}\text { Controls } \\
(n=12)\end{array}$ & $\begin{array}{l}\text { Stable } \\
(n=29)\end{array}$ & $\begin{array}{l}\text { Unstable } \\
(n=15)\end{array}$ \\
\hline Sex (M:F) & $6: 6$ & $13: 16$ & $7: 8$ \\
Age (years) & $37(2)$ & $27.5(1)$ & $31(2)$ \\
FEV $(\%$ predicted $)$ & $95(1)$ & $61(5)$ & $47(6)$ \\
PA in sputum & & $12 / 20$ & $12 / 12$ \\
Corticosteroid treatment & & 6 & 5 \\
\hline
\end{tabular}

All values expressed as mean (SE).

$\mathrm{PA}=$ Psedomonas aeruginosa .

acceptable manoeuvre for the CO measurement were excluded. After the initial evaluation patients were divided into two groups according to the presence or absence of a respiratory exacerbation. Criteria for a respiratory exacerbation were considered the presence of one or more of the following symptoms: increased cough, increased sputum production, change in the quality of the sputum (more purulent, increased "thickness", or presence of blood), sensation of increased chest congestion, increased dyspnoea, or decreased exercise tolerance and worsening of $\mathrm{FEV}_{1}{ }^{23}$ According to these criteria 29 patients were included in the stable CF group and 15 patients with mild to moderate respiratory exacerbations were included in the unstable CF group. The characteristics of the healthy subjects and patients are summarised in table 1 .

\section{STUDY DESIGN}

This was a cross sectional study of a population of CF patients with and without exacerbations. In order to assess whether exhaled $\mathrm{CO}$ was reduced during the course of intravenous antibiotics we measured exhaled CO concentrations in seven patients admitted with a respiratory exacerbation for the administration of intravenous antibiotics. All subjects and patients gave informed consent to participate in the study which was approved by the local ethical committee.

\section{MEASUREMENTS}

Exhaled CO was measured by a modified electrochemical sensor with sensitivity from 1 part per million (ppm) to $500 \mathrm{ppm}$ of CO, simultaneously with exhaled $\mathrm{NO}$ and carbon dioxide $\left(\mathrm{CO}_{2}\right)$ by LR2000 chemiluminescence analyser (Logan Research Ltd, Rochester, Kent, UK) to control exhalation parameters (resistance 3 (0.4) $\mathrm{mm} \mathrm{Hg}$; exhalation flow 5-6 1/min). The detection limit for $\mathrm{CO}$ was $0.1 \mathrm{ppm}$. The analyser was calibrated weekly with a CO calibration gas and daily with NO calibration gas (Bedfont Scientific Ltd, Kent, and BOC Gases, Guildford, respectively). Ambient $\mathrm{CO}$ was recorded before every measurement of exhaled $\mathrm{CO}$ in all subjects. For exhaled $\mathrm{CO}$ and NO measurements the subjects exhaled slowly from total lung capacity over $15-20$ seconds at an exhalation flow rate of $5-61 / \mathrm{min}$. The mean value of the two measurements was recorded and the ambient $\mathrm{CO}$ was subtracted from the $\mathrm{CO}$ value to obtain the final result. All patients whose exhaled $\mathrm{CO}$ and $\mathrm{NO}$ concentrations were measured found it very easy to perform and all of them were able to do a correct manoeuvre after a single training session. No special skills were needed to perform this test and none of the patients was excluded because of an incorrect technique.

$\mathrm{FEV}_{1}$ was recorded using a Vitalograph Compact (Vitalograph Ltd, Buckingham, $\mathrm{UK})$. The deterioration in $\mathrm{FEV}_{1}$ was calculated using the $\mathrm{FEV}_{1}$ measured at the moment of the initial evaluation and the $\mathrm{FEV}_{1}$ recorded in a stable condition within the last year.

\section{STATISTICAL ANALYSIS}

All variables are expressed as mean (SE). Patients and control groups were compared using the Student's $t$ test. FEV 1 and exhaled $\mathrm{CO}$ were analysed by linear regression. A p value of $<0.05$ was considered statistically significant. Analysis of results was performed by using GraphPad Prism (GraphPad Software Inc, San Diego, USA).

\section{Results}

\section{CLINICAL PARAMETERS}

Age and sex distribution were comparable between the stable and unstable $\mathrm{CF}$ groups (table 1). In the unstable group all 15 patients presented with increased cough and sputum production, nine patients also had increased dyspnoea or decreased exercise tolerance and changes in the quality of sputum, and eight had the sensation of chest congestion.

In the stable CF group the mean $\mathrm{FEV}_{1}$ was $2.24(0.2) 1$ which was comparable to a previous stable $\mathrm{FEV}_{1}$ recorded within the last year of $2.31(0.2) 1$. In the unstable CF group the mean $\mathrm{FEV}_{1}$ was $1.6(0.1) 1$ while the previously measured $\mathrm{FEV}_{1}$ when the patients were stable was $1.87(0.1) 1$. The deterioration in $\mathrm{FEV}_{1}$ was not statistically significant but the overall fall in $\mathrm{FEV}_{1}$ in the unstable group was $14.8(2.9) \%$ (table 2).

Thirty two sputum cultures were performed. Of the 20 sputum cultures from patients with stable CF $12(60 \%)$ were positive for Pseudomonas aeruginosa $\left(>10^{5} \mathrm{cfu} / \mathrm{ml}\right)$, seven $(35 \%)$ had other pathogens (Staphylococcus aureus, Haemophilus influenzae), and one sputum culture had normal flora. All 12 sputum cultures from patients with unstable CF were positive for Pseudomonas aeruginosa $\left(>10^{5} \mathrm{cfu} /\right.$ $\mathrm{ml})$.

Table 2 Change in forced expiratory volume in one second $(F E V$ ) in patients with respiratory exacerbation

\begin{tabular}{lllll}
\hline No. & Sex & $\begin{array}{l}\text { Previous stable } \\
F E V_{1}(l)\end{array}$ & $\begin{array}{l}\text { Current } \\
F E V_{I}(\text { l) }\end{array}$ & $\begin{array}{l}\text { \% change } \\
\text { in FEV }\end{array}$ \\
\hline 1 & $\mathrm{~F}$ & 3.65 & 3.43 & -6.0 \\
2 & $\mathrm{M}$ & 1.64 & 1.44 & -12.2 \\
3 & $\mathrm{M}$ & 1.08 & 0.86 & -20.4 \\
4 & $\mathrm{M}$ & 1.7 & 1.4 & -17.6 \\
5 & $\mathrm{~F}$ & 1.14 & 0.64 & -43.9 \\
6 & $\mathrm{M}$ & 1.87 & 1.27 & -32.1 \\
7 & $\mathrm{~F}$ & 2.42 & 1.95 & -19.4 \\
8 & $\mathrm{M}$ & 2.3 & 1.9 & -17.4 \\
9 & $\mathrm{~F}$ & 2.96 & 2.42 & -18.2 \\
10 & $\mathrm{~F}$ & 1.56 & 1.43 & -8.3 \\
11 & $\mathrm{M}$ & 1.12 & 0.98 & -12.5 \\
12 & $\mathrm{~F}$ & 2.63 & 2.42 & -8.0 \\
13 & $\mathrm{~F}$ & 1.09 & 1.14 & 4.6 \\
14 & $\mathrm{M}$ & 1.7 & 1.6 & -5.9 \\
15 & $\mathrm{~F}$ & 1.24 & 1.11 & -10.5 \\
\hline
\end{tabular}




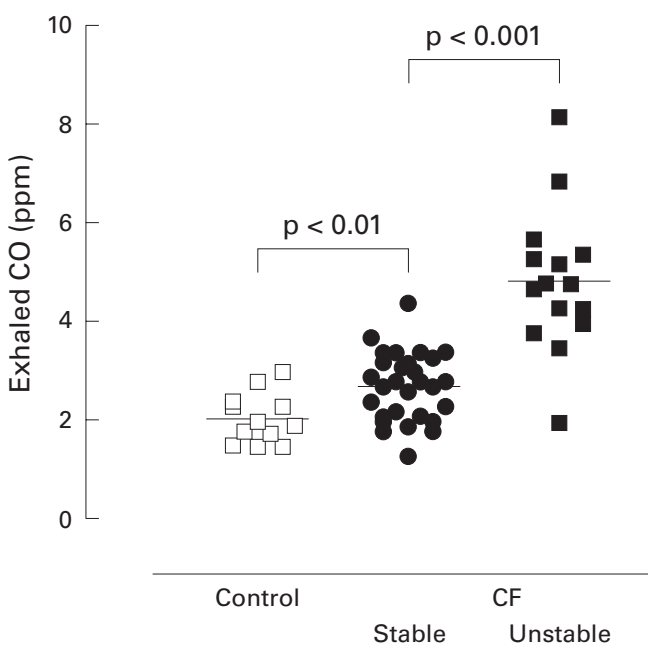

Figure 1 Exhaled carbon monoxide (CO) in normal subjects and in cystic fibrosis patients with stable disease (stable CF) and with infective respiratory exacerbations (unstable CF).

\section{EXHALED CO}

The exhaled CO concentration was $2.0(0.1)$ $\mathrm{ppm}$ in the control group, $2.7(0.1) \mathrm{ppm}$ in the stable CF group (difference between means -0.67 (0.22), $95 \%$ confidence interval (CI) 0.22 to $1.12, \mathrm{p}<0.01)$, and $4.8(0.3) \mathrm{ppm}$ in the unstable group (difference between means -2.82 (0.44), 95\% CI 1.91 to 3.72, p<0.0001). When the values from stable and unstable CF patients were compared the mean differences were statistically significant (differences between means $-2.15(0.32), 95 \%$ CI 1.50 to $2.79, \mathrm{p}<0.001$; fig 1$)$.

\section{EXHALED NO}

The exhaled NO concentration was 7.3 (0.24) ppb in normal controls, $5.7(0.29) \mathrm{ppb}$ in stable CF patients, and $6.1(0.72) \mathrm{ppb}$ in unstable CF patients. There was a significant difference between control subjects and CF stable patients (difference between means 1.58 $(0.48), 95 \% \mathrm{CI}-2.54$ to $-0.62, \mathrm{p}<0.01)$ but the difference between control subjects and unstable patients was not significant.

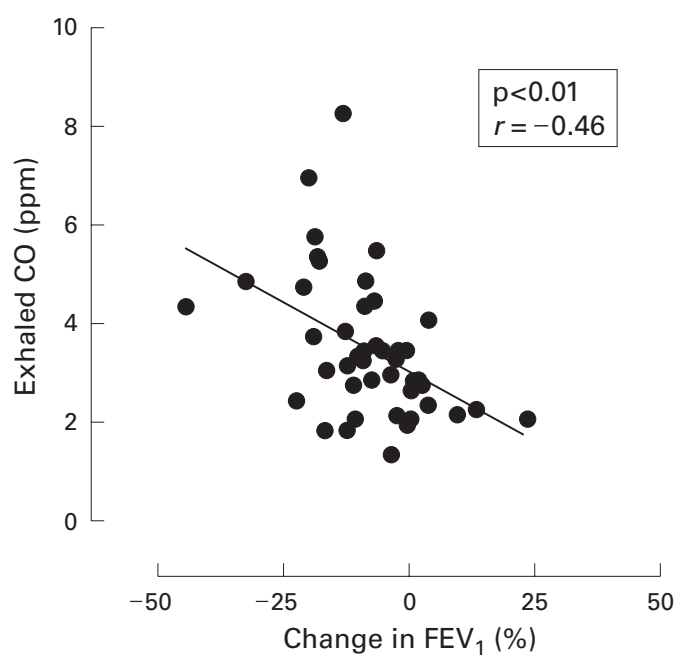

Figure 2 Correlations between percentage change in forced expiratory volume in the first second (FEV) and exhaled carbon monoxide (CO).

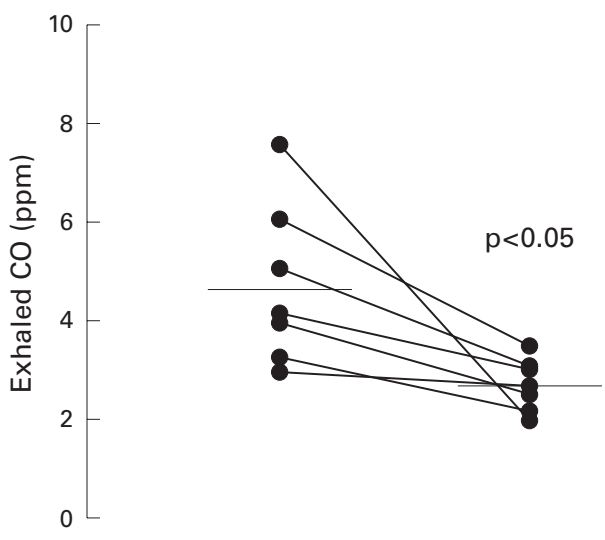

$$
\text { Admission Day } 7
$$

Figure 3 Exhaled carbon monoxide (CO) in patients with infective respiratory exacerbation at admission and after seven days of intravenous antibiotics.

\section{CORRELATIONS}

There was a significant correlation between exhaled CO concentrations and the percentage change in $\mathrm{FEV}_{1}(r=-0.46, \mathrm{p}<0.01$; fig 2$)$ but there was no correlation between exhaled NO concentrations and $\mathrm{FEV}_{1}(r=0.06, \mathrm{p}>0.05)$.

EFFECT OF PSEUDOMONAS INFECTION

Exhaled CO concentrations in stable CF patients with a positive Pseudomonas aeruginosa sputum culture were $2.82(0.1)$ ppm compared with $2.88(0.2) \mathrm{ppm}$ in stable CF patients infected with other pathogens. The mean difference was not statistically significant.

EFFECT OF CORTICOSTEROID TREATMENT

Eleven patients were treated with corticosteroids (oral or inhaled), six in the stable CF group and five in the unstable $\mathrm{CF}$ group. Exhaled $\mathrm{CO}$ and $\mathrm{NO}$ concentrations from patients receiving corticosteroid treatment were not significantly different from those who were not.

EFFECT OF ANTIBIOTIC TREATMENT

In order to assess whether exhaled $\mathrm{CO}$ is reduced during the course of intravenous antibiotics we measured exhaled $\mathrm{CO}$ concentrations in seven patients who were admitted with a respiratory exacerbation for the administration of intravenous antibiotics. At the time of admission their exhaled $\mathrm{CO}$ concentration was $4.7(0.6) \mathrm{ppm}$ and after seven days of treatment and improvement of symptoms and $\mathrm{FEV}_{1}$ it decreased to $2.7 \quad(0.1) \mathrm{ppm}$ (mean of differences 2.04, 95\% CI 0.45 to $3.64, \mathrm{p}<0.05$; fig 3).

\section{Discussion}

This study shows that exhaled CO concentrations are increased in patients with $\mathrm{CF}$ and there is a further increase when a clinical worsening of the lung disease is present. Exhaled $\mathrm{CO}$ concentrations are increased in inflammatory lung diseases including asthma, ${ }^{6}$ upper respiratory tract infections, ${ }^{7}$ bronchiectasis, ${ }^{8}$ and cystic fibrosis. ${ }^{9}$ Furthermore, increased levels of exhaled $\mathrm{CO}$ were found to be associated with increased expression of HO-1 
in airway macrophages from asthmatic patients. ${ }^{24}$ These data suggest increased HO-1 activity in response to inflammation and oxidative stress and this may serve as an adaptive mechanism to protect cells from oxidative damage. ${ }^{2526}$ In our study stable CF patients had higher levels of exhaled $\mathrm{CO}$ than controls. This agrees with previous findings of Konstan et $a l^{1}$ who demonstrated significant infection and inflammation in adolescents and adults with mild lung disease without symptoms of active infection. There is also agreement with our data showing increased levels of exhaled $\mathrm{CO}$ in stable CF patients when compared with normal controls, ${ }^{9}$ although the levels of exhaled $\mathrm{CO}$ in our current study were different because of differences in the methodology of $\mathrm{CO}$ measurement. The higher concentration of exhaled $\mathrm{CO}$ in the unstable group may reflect further induction and activation of $\mathrm{HO}-1$ in the airways in response to infection, increased inflammation, and increased oxidative stress.

The most characteristic feature of inflammation in the lungs of patients with $\mathrm{CF}$ is the persistent infiltration of large numbers of activated neutrophils which release reactive oxygen species and proteases (including elastase) that cause direct damage to the airway wall. ${ }^{27}$ The activation of neutrophils induces a respiratory burst which results in increased production of superoxide anions $\left(\mathrm{O}_{2}^{-}\right)$and hydrogen peroxide $\left(\mathrm{H}_{2} \mathrm{O}_{2}\right){ }^{28}$ These data support our hypothesis that during exacerbations there is further oxidative stress as reflected by increased exhaled CO. The presence of Pseudomonas aeruginosa in the sputum culture from stable CF patients did not modify the levels of exhaled $\mathrm{CO}$ and suggests that no further activation of HO-1 may be possible in the presence of Pseudomonas aeruginosa.

There was a significant correlation between exhaled $\mathrm{CO}$ levels and the change in $\mathrm{FEV}_{1}$, showing that a deterioration in $\mathrm{FEV}_{1}$ along with the presence of respiratory symptoms of an infectious exacerbation are linked to an increase in exhaled CO. The overall trend shows a negative correlation between change in $\mathrm{FEV}_{1}$ and exhaled concentration of $\mathrm{CO}$.

Increased levels of exhaled $\mathrm{CO}$ measured at the time of admission were significantly reduced following antibiotic treatment, suggesting that the activation of HO-1 during an exacerbation was downregulated by antibiotics. We found that measurement of the concentration of exhaled CO may be a useful test for the assessment of patients with CF and an indicator of deterioration and recovery from a respiratory exacerbation. In addition, we found a wide range of baseline levels of exhaled CO among stable and unstable patients which probably led to the overlap of $\mathrm{CO}$ values seen in figs 2 and 3 so we hypothesised that there is a different degree of oxidative stress in patients with a similar clinical condition. Exhaled CO values should therefore be considered as an individual measurement in each patient, and exhaled $\mathrm{CO}$ values recorded at the best clinical condition represent a baseline value with which future measurements can be compared during follow up.
Exhaled NO levels in stable CF patients were lower than controls and, although there was a statistical difference between controls and stable CF patients, it was not clinically relevant; there was no significant difference between stable and unstable CF patients. These data support previous reports showing a reduced expression of iNOS in airway epithelial cells from patients with $\mathrm{CF},{ }^{17}{ }^{18}$ or a reduced exhaled NO due to combination of oxygen radicals released from neutrophils with NO to form peroxynitrite. ${ }^{29}$ It also shows that exhaled $\mathrm{CO}$ is a better marker of oxidative stress in cystic fibrosis.

In summary, exhaled $\mathrm{CO}$ concentrations are increased in stable CF patients and there is a further increase during mild to moderate exacerbations of the lung disease. The measurement of exhaled levels of $\mathrm{CO}$ could therefore be a useful test for monitoring patients with $\mathrm{CF}$ in order to assess airway inflammation in a non-invasive way, and prospective studies of its value in detecting early deterioration are now indicated.

1 Konstan MW, Hilliard KA, Norvell TM, et al. Bronchoalveolar lavage findings in cystic fibrosis patients with stable, clinically mild lung disease suggest ongoing infection and inflammation. Am $¥$ Respir Crit Care Med infection and inf

2 Wilson R, Dowling RB. Lung infections. 3. Pseudomonas aeruginosa and other related species. Thorax 1998;53:213

3 Brown RK, Kelly FJ. Role of free radicals in the pathogenesis of cystic fibrosis. Thorax 1994;49:738-42.

4 Brown RK, Wyatt H, Price JF, et al. Pulmonary dysfunction in cystic fibrosis is associated with oxidative stress. Eur Respir 7 1996;9:334-9.

5 Hull J, South M, Phelan P, et al. Surfactant composition in infants and young children with cystic fibrosis. Am F Respir Crit Care Med 1997;156:161-5.

6 Dominguez C, Gartner S, Linan S, et al. Enhanced oxidative damage in cystic fibrosis patients. Biofactors 1998;8:14953

7 Choi AM, Alam J. Heme oxygenase-1: function, regulation, and implication of a novel stress-inducible protein in oxidant-induced lung injury. Am $\mathcal{f}$ Respir Cell Mol Bio 1996;15:9-19.

8 Zayasu K, Sekizawa K, Okinaga S, et al. Increased carbon monoxide in exhaled air of asthmatic patients. Am J Respir Crit Care Med 1997;156:1140-3.

9 Yamaya M, Sekizawa K, Ishizuka S, et al. Increased carbon monoxide in exhaled air of subjects with upper respiratory tract infections. Am f Respir Crit Care Med 1998;158:311-

10 Horváth I, Loukides S, Wodehouse T, et al. Increased levels of exhaled carbon monoxide in bronchiectasis: a new marker of oxidative stress. Thorax 1998;53:867-70.

11 Paredi P, Shah PL, Montuschi P, et al. Exhaled carbon monoxide is elevated in cystic fibrosis. A new test for disease monitoring? Thorax 1999;54:917-20.

12 Barnes PJ. Nitric oxide and airway disease. Ann Med 1995; 27:389-93.

13 Kharitonov SA, Yates D, Robbins RA, et al. Increased nitric oxide in exhaled air of asthmatic patients. Lancet 1994,343 133-5.

14 Kharitonov SA, Wells AU, O'Connor BJ, et al. Elevated levels of exhaled nitric oxide in bronchiectasis. Am ₹ Respir Crit Care Med 1995;151:1889-93.

15 Kharitonov SA, Yates D, Barnes PJ. Increased nitric oxide in exhaled air of normal human subjects with upper respiratory tract infections. Eur Respir f 1995;8:295-7.

16 Kanazawa H, Shoji S, Yamada M, et al. Increased levels of nitric oxide derivatives in induced sputum in patients with asthma. F Allergy Clin Immunol 1997;99:624-9.

17 Dotsch J, Demirakca S, Terbrack HG, et al. Airway nitric oxide in asthmatic children and patients with cystic fibrosis. Eur Respir F 1996;9:2537-40.

18 Ho LP, Innes JA, Greening AP. Exhaled nitric oxide is not elevated in the inflammatory airways diseases of cystic fibrosis and bronchiectasis. Eur Respir f 1998;12:1290-4.

19 Kelley TJ, Drumm ML. Inducible nitric oxide synthase expression is reduced in cystic fibrosis murine and human airway epithelial cells. 7 Clin Invest 1998;102:1200-7.

20 Meng QH, Springall DR, Bishop AE, et al. Lack of inducible nitric oxide synthase in bronchial epithelium: a possible mitric oxide synthase in bronchial epithelium: a possible Pathol 1998;184:323-31.

21 Jones KL, Bryan TW, Jinkins PA, et al. Superoxide released from neutrophils causes a reduction in nitric oxide gas. $A m$ f Physiol 1998;275:L1120-6. 
22 Ho LP, Innes JA, Greening AP. Nitrite levels in breath condensate of patients with cystic fibrosis is elevated in contrast to exhled nitric oxide. Thorax 1998;53: 680-4.

23 Grasemann H, Ioannidis I, Tomkiewicz RP, et al. Nitric oxide metabolites in cystic fibrosis lung disease. Arch Dis Child 1998;78:49-53.

24 Linnane SJ, Keatings VM, Costello CM, et al. Total sputum nitrate plus nitrite is raised during acute pulmonary infection in cystic fibrosis. Am $\mathcal{F}$ Respir Crit Care Med 1998;158: 207-12.

25 Marshall B, Samuelson W. Basic therapies in cystic fibrosis Clin Chest Med 1998;19:487-504.
26 Horváth I, Donnelly LE, Kiss A, et al. Raised levels of exhaled carbon monoxide are associated with an increased expression of heme oxygenase- 1 in airway macrophages in asthma: a new marker of oxidative stress. Thorax 1998;53:668-72.

27 Poss KD, Tonegawa S. Reduced stress defence in heme oxygenase 1-deficient cells. Proc Natl Acad Sci USA 1997;94: 10925-30.

28 Willis D, Moore AR, Frederick R, et al. Heme oxygenase: a novel target for the modulation of the inflammatory response. Nature Med 1996;2:87-90.

29 Konstan MW, Berger M. Current understanding of the inflammatory process in cystic fibrosis: onset and etiology. Pediatr Pulmonol 1997;24:137-42. 